\title{
Opioid Bağımlılığının Tedavisinde Metadon ve Buprenorfin'in Etkinliği: Hangisini Kullanalım?
}

\author{
Mehmet ÇAKICI ${ }^{1}$, Damla ARAZ ${ }^{2}$, Elif AKSOY ${ }^{2}$, Ayşe GÖKYİĞİT ${ }^{3}$
}

\begin{abstract}
Özet: Opioid bağımlılı̆̆ı, tüm kültürleri etkileyen, sosyal problemler yaratan, bireyin sağlı durumunu etkileyerek ölüme yol açan dünyanın en büyük sağlık ve sosyal problemlerinden biridir. Opiyatların bağımlılığının tedavisinde çok seçenekli ilaç çeşitleri bulunmaktadır. Buprenorfin ve Metadon opioid bağımlılı̆̆ının tedavisinde başlıca ve en etkin kullanılan iki ajandır. Her iki ajanın da yapısal olarak birbirine benzemekle beraber kullanımında avantajları olduğu gibi dezavantajları da bulunmaktadır. Bu ilaçlar doğru kullanıldı̆̆ında, bağımlıların opiyatların kullanımına olan isteklerini azaltmaktadırlar. Metadon ile Buprenorfin aşırı doz kullanım olasılığı düşük olduğu için opiyatların bağımlılı̆̆ının tedavisinde daha güvenli bir seçenek olarak görülmektedir. Özellikle psikososyal müdahalelerle birlikte kullanıldığında, opioid bağımlılığı için hem Metadon hem de Buprenorfin diğer tüm tedavi türlerinden daha etkili olduğu gösterilmiştir. Bu derlemenin amacı Buprenorfin ve Metadonun benzerliklerini, farklılıklarını ve birbirine yönelik üstünlüklerini tartışarak opioid bağımlılığı tedavisindeki her iki ilacın da rolünü bilimsel olarak ele almaktır. Böylece opioid bağımlılı̆̆ı tedavisi ile ilgili uzmanlara, araştırmacılara ve politika geliştiricilerine genel bir bilgi sunarak bağımlılar için etkin ve çok seçenekli tedavi yöntemlerine katkı koymak hedeflenmiştir.
\end{abstract}

Anahtar kelimeler: Opioid Bağımlılı̆̆ , Buprenorfin, Metadon

\section{Efficacy Of Methadone and Buprenorphine İn The Treatment Of Opioid Dependence: Which Should We Use?}

\begin{abstract}
Abstratct: Opioid addiction is one of the biggest health and social problems in the world, affecting all cultures, creating social problems, and affecting the individual's health. There are multiple choice of drugs for the treatment of opiate dependence. Buprenorphine and Methadone are the two main and most effective agents in the treatment of opioid dependence. Both agents are structurally similar, but have advantages and disadvantages in their use. When these drugs are used correctly, they reduce the desire of the addicts to use opiates. Methadone and Buprenorphine are considered to be a safer option in the treatment of opiate dependence because of the low probability of overdose. Especially when used in conjunction with psychosocial interventions, both Methadone and Buprenorphine have been shown to be more effective than any other treatment for opioid dependence. The aim of this review is to discuss the similarities, differences and superiorities of Buprenorphine and Methadone and discuss the role of both drugs in the treatment of opioid dependence scientifically. Thus, it is aimed to contribute to effective and multi-choice treatment methods for addicts by providing general information to experts, researchers and policy makers about opioid addiction treatment.
\end{abstract}

Keywords: Buprenorphine, Methadone, Opioid Addiction.

${ }^{1}$ Prof. Dr., Yakın Doğu Üniversitesi, Psikoloji Bölümü, Lefkoşa-Kıbrıs

${ }^{2}$ Psk., Yakın Doğu Üniversitesi, Psikoloji Bölümü, Lefkoşa-Kıbrıs

${ }^{3}$ İlaç ve Eczacılık Dairesi, Lefkoşa, KKTC.

Address of correspondence/ Yazışma adresi: Prof. Dr. Mehmet Çakıcı, Yakın Doğu Üniversitesi, Fen-Edebiyat Fakültesi, Psikoloji Bölümü, Lefkoşa-Kıbrıs. E-mail: meh_cakici@yahoo.com

Date of Received/Geliş Tarihi: 30.07.2019,Date of Revision/Düzeltme Tarihi: 04.11.2019 Date of Acceptance/Kabul Tarihi: 10.11.2019

Citing/ Referans Gösterimi: Çakıcı, M., Araz, D., Aksoy, E., Gökyiğit, A. (2019). Opioid Bağımlılığının Tedavisinde Metadon ve Buprenorfin'in Etkinliği: Hangisini Kullanımı? Klbris Türk Psikiyatri ve Psikoloji Dergisi, 1(3): 194-99 doi:10.35365/ctjpp.19.1.25 


\section{Giriş}

Genellikle Eroin bağımlılı̆g olarak bilinen opioid bağımlılığı, tüm kültürleri etkileyen, sosyal problemler yaratan, bireyin sağlık durumunu etkileyerek ölüme yol açan ve uluslararası kaçakçılık ortamı oluşturması açısından dünyanın en büyük sağlık ve sosyal problemlerinin başında gelenlerindendir (Rosenblum, Marsch ve ark., 2008). Opioidler toplumda birçok rol oynamaktadır. Bunlar kötüye kullanım, bağımlılık ve saptırmanın tehlikeli sonuçlarıyla bağlantılı bileşiklerdir (Rassol, 2010). Tarihsel açıdan bağımlılıkla ilgili toplumdaki kaygılar görünüş olarak kanser ağrısı, akut ağr1 gibi opioid tedavisine uygun olduğu düşünülen bozuklukların giderilmesine edilmesine katkı sağlamıştır (Rosenblum, Marsch ve ark. 2008). Opiatlar, doğal olarak veya sentetik olarak türetilen, morfine benzer etkileri olan psikoaktif bir madde olarak tanımlanan bir ilaç sınıfıdır. Bunlar kodein, oksikodon, eroin, Metadon ve Buprenorfin gibi ilaçlardır (Rassol, 2010). Opiyatlar, akut, kronik veya cerrahi ağrının ağrı yönetimi için hastalara yasal olarak da reçete edilebilmektedirler (Yule, Lyons, ve Wilens, 2018). Opioidler ağn1 tedavisinde kullanılan en etkili ilaçlar arasındadır. Akut şiddetli ağrı ve ileri tıbbi hastalıklara bağlı kronik ağrıların tedavisinde kullanımları dünyanın birçok yerinde bakım standardı olarak kabul edilir (Rosenblum, Marsch ve ark. 2008). Bu ilaçları uzun vadede alan hastalar genellikle bir tolerans geliştirir veya analjezi elde etmek için artan dozajlara ihtiyaç duyarlar. Bu maddeleri kullanan kişiler yoksunluk semptomlarını önlemek için dozu giderek artırmaları ile opioid bağımlısı olabilmektedirler (Rassol, 2010). Bununla birlikte, bazı insanlar, tıbbi, yasal ve sosyal sonuçlara rağmen ve reçete edilenlerden başka amaçlar için yasadışı ilaç kullanımı olarak tanımlanan opiyatlara bağımlılık geliştirebilmektedirler (Papadakis, M.A ve McPhee, S.J. 2014). Opiyat bağımlılığında tolerans gelişimi daha fizyolojik olmakla birlikte bağımlılık genellikle psikolojik niteliklerle de ilişkilidir (Papadakis, M.A. ve McPhee S.J. 2014). Bağımlılık herhangi bir kişide ortaya çıkabilmektedir. Opioid kullanımına bağlı ortaya çıkanan aljezik ve öforik etkiler birçok birey için yüksek bir bağımlılık potansiyeli oluşturmaktadır (Rosenblum, Marsch ve ark. 2008). Özellikle bu bağımlılık potansiyeli gençler üzerine daha çok yoğunlaşmaktadır (Yule, Lyons, ve Wilens, 2018).

Küresel olarak, 13 milyon enjeksiyon ile psikoaktif madde kullanan kişi bulunduğu ve bunun da 9,2 Milyonunun eroin kullanıcısı olduğu tahmin edilmektedir (WHO, 2004). Birleşmiş Milletler Madde Kontrol Programı, Fransa, Almanya, Hollanda, İtalya, İspanya ve İngiltere'de 15 yaş üstü eroin kullanım yaygınlığının $\% 0,11$, Hindistan ve Bangladeş gibi Güneydoğu Asya Ülkelerinde \%0,15 olduğunu bildirmektedir (United Nations Drug Control Programme, 2000). BM Madde ve Suç Ofisi'nin Dünya Raporu'na göre son bir yıldaki opioid kullanım yaygınlığının Batı Avrupa ve Kuzey Amerika'da \%0,4-0,5 ve Güney Doğu Asya'da \%0,2-0,4 arasında bulunduğu bildirilmektedir (United Nations Office on Drug sand Crime, 2009).

Opioid kötüye kullanımı ile ilgili yüksek tıbbi ve psikiyatrik komorbiditeler göz önüne alındığında, hem birinci basamak hekimler hem de ruh sağlığ1 uzmanları düzenli olarak reçeteli ve yasadışı opioid bağımlılı̆̆ sekeli ile karşı karşıya kalmaktadır (Gwin Mitchell ve ark. 2009; Sohler ve ark. 2010). Bu artan ve büyüyen eroin kullanımı nedeniyle ABD, İngiltere, Fransa, Avustralya, Kanada gibi pek çok Batı ülkesinde, hem Metadon hem de Buprenorfin ile eroinden detoksifikasyon ve opioid idame tedavisi güncel tedaviler olarak kullanılmaktadır (Whelan ve Remski, 2012).Özellikle psikososyal müdahalelerle birlikte kullanıldığında, opioid bağımlılığı için hem Metadon hem de Buprenorfin diğer tüm tedavi türlerinden daha etkili olduğu gösterilmiştir (Amato ve ark. 2011).Bu ilaçların eroin bağımlılığı tedavisindeki güvenlik özellikleri, sürekli yasadışı uyuşturucu kullanımının zararlarına karşı faydası tartışılması gerekmektedir. Burada düşünülen tüm opioid replasman tedavileri potansiyel olarak ölüme neden olabilir, ancak eroin kullanımının devam etmesi yüksek morbidite ile ilişkili olmaktadır. Örneğin, Caplehorn ve Drummer, metadon bakımının bir yılda kaybedilen her biri için iki can kurtardığını tespit etmiştir (Whelan ve Remski, 2012). KKTC'de 2002'de ve Türkiye'de de 2010'da Buprenorfin izni alınmıştır. Türkiye'de Metadon izni bulunmaktadır ancak KKTC'de Metadon izni bulunmamaktadır. Buprenorfin'in özellikle Türkiye'de ve KKTC'de yaygın kullanımına karşın Metadon daha eski bir ilaç olmasına rağmen kullanıma geçilmemiştir. $\mathrm{Bu}$ derlemede Buprenorfin ve Metadonun benzerliklerini, faklılıklarını ve birbirine yönelik üstünlüklerini tartışarak özellikle Metadon'un opioid bağımlılığı tedavisindeki rolünü bilimsel olarak ele almak amaçlanmıştır.

\section{Buprenorfin ve Metadon}

Buprenorfin ve Metadonopioid bağımlılı̆̆ının tedavisinde başlıca ve en etkin kullanılan iki ajandır (Bavelonni, Piazzi ve ark. 2015). İngiltere ve diğer birçok Batı ülkelerinde, hem Metadon hem de Buprenorfin, ilgili kurumlar tarafindan eroinden detoksifikasyon amaciyla opioid tedavisi için önerilmektedir (Whelan ve Remski, 2012).2000'lerin ortalarından önce İngiltere'de en çok kullanılan ajan kodein tabletleriydi(Wright ve ark. 2011). Özellikle ABD'de Metadon tedavisi en yaygın kullanılan ajandı. Bağımlılık tedavisinde başarısına rağmen, yıllar geçtikçe, Metadona yönelik de bağımlılıklar artınca başka arayışlar gündeme geldi. Artan Metadonun kötüye kullanımı ve bağımlılığı tehlikesine yanıt olarak, İngiliz ilaç şirketi Reckitt Benckiser 2002 yılında Subokson (Buprenorfine/Nalokson) adlı bir ilaç piyasaya sürdü (Amato ve ark. 2011). Buprenorfin ve Nalokson kombinasyonu olan bu ilaç, metadon için olası bir yedek olarak ilan edilmişti. Kısmi bir opioidagonisti olarak (tam agonistmetadon ile karşılaştırıldığında), bilim adamları Subokson'un, yüksek kötüye kullanım potansiyeli olmaksızın bireylere Metadonla aynı faydaları sunacağını savunmuştur (Whelan ve Remski, 2012).Öncül sonuçlar heyecan vericiydi ve dünyadaki tıp ve bağımlılık uzmanları, suboksonun kötüye kullanım riski olmadan Metadon kadar etkili olup olmadığını hep merak etmişlerdir. Bugün İngiltere, ABD, Avustralya ve bazı bat Avrupa ülkelerinde Metadon ve Buprenorfin eroin bağımlılığının yoksunluğunun tedavisinde ve ayrıca idame tedavisinde birincil farmakoterapi seçeneğidir (Whelan ve Remski, 2012). Ayrıca Hindistan başta olmak üzere Güney doğu Asya Ülkelerinde de her iki ilaçda hastaların teşhis durumuna göre Batı ülkelerindeki benzer tedavi yöntemlerinde kullanılmaktadırlar (Clinical practice guidelines for management of opioid dependence, 2004). 
Opioid agonistleri Buprenorfin ve Metadon, opioid reseptörlerini bloke eden yerine koyma tedavisi ajanları olarak bilinmektedirler (Rosenblum, Marsch ve ark. 2008). Metadon tam opioidagonisti ve Buprenorfin ise parsiyel opioid agonistidir. Hem Buprenorfin hem de Metadonmu ve delta reseptör alt tipleri vasitasıyla adenil siklaz aktivitesine aracilik eder ve endorfinler ve enkefalinler gibi endojen opioidlerin salınmasına yol açan içten rektifiye edici potasyum kanallarının aktivasyonuna neden olarak etki gösterirler (Whelan ve Remski, 2012). Her iki ajanın da farklılıkları kendi avantajları ve dezavantajları olmasıdır. Rehabilitasyon programlarında genellikle opioid ikame maddesi olarak Metadon veya Buprenorfin kullanılmaktadır (Whelan ve Remski, 2012). Her iki opioid agonisti, eroin veya oksikodon gibi tehlikeli opioidlerin beyne bağlanmasını önlemektedirler (Amato ve ark. 2011). Ayrıca, öfori hissi de üretebilirler, ancak etkileri çok daha azdır. $\mathrm{Bu}$ ilaçlar doğru kullanıldığında, bağımlıların yasadışı uyuşturuculara olan isteklerini azaltmaktadırlar (Whelan ve Remski, 2012). Doğru kullanıldığında, reçeteli ilaçlara göre aşırı doz kullanımı olasılığı daha düşük olduğu için daha güvenli bir seçenek olarak görülmektedir.

\section{Metadon:}

Neredeyse elli yıldır, opiat bağımlılı̆̆ının tedavisinin birincil aracı olmuştur. Amerika Birleşik Devletleri, Gıda ve İlaç İdaresi (FDA) tarafindan 1947 'de analjezik ve antitussif kullanımlar için onaylanan Metadonun, 1960'ların ortalarında afyon bağımlılığının tedavisinde etkili olduğu gösterilmiş ve 1972'nin sonlarında FDA tarafından onaylanmıştır (Rettig ve Yarmolinsky, 1995). Metadon İngiltere, ABD, Avusturalya ve Avrupa'nın bazı bölgelerinde eroin bağımlılığını tedavi edebilmek için kullanılan en yaygın ilaçtır (Whelan ve Remski, 2012).

Metadon, hastaların tolerans geliştirmelerine neden olmadan madde isteğini ve yoksunluk belirtilerini hafifletir. Böyle olunca bağımlı hastaya günlük olarak alabileceği ve sürekli sonuç almak için dozunu artırmasını gerektirmeyeceği bir kullanıma imkan vermektedir. Metadon, beynin $\% 70$ opioid reseptörünü serbest bırakarak reseptörlerin yaklaşık \%30'una bağlanmaktadır (Rosenblum, Marsch ve ark. 2008). Metadon, opioid bağımlılarının isteklerini azaltarak, eroin veya diğer tehlikeli opioidlere tekrar kaymalarını engel olmaktadır. Aşırı doz opioid kullanımı ile ilgili ölümler genellikle solunum depresyonu şeklinde olmaktadır ve önemli bir problem yaratmaktadır (Whelan ve Remski, 2012). Araştırmalar metadonun, bağımlıları aşırı doz veya ölüme neden olabilecek tehlikeli sokak uyuşturucularından kurtarmanın etkili bir yolu olduğunu ortaya koymuşlardır (Rosenblum, Marsch ve ark. 2008). Sonuç olarak yapılan çalışmalar Metadonun bağımlılık tedavisinde önemli ve etkili bir seçenek olduğunu göstermiştir (Whelan ve Remski, 2012).

\section{Buprenorfin:}

Buprenorfin, 1960'larda opioid bağımlılığının tedavisinde kullanılmaya başlandı (Whelan ve Remski, 2012). Buprenorfin sadece kısmi bir agonisttir. Buprenorfin hem arındırma hemde idame tedavisinde kullanılabilmektedir (Johnson, Strain veAmass, 2003). Avrupa'da, Buprenorfin, birinci basamak sağlık kuruluşlarında, opioid bağımlılığının tedavisinde Metadonun bir alternatifi olarak yaygın bir şekilde kullanılmıştır (Auriacombe ve ark. 2004). ABD'de, Buprenorfin ve Buprenorfin-Nalokson, 2002'de ABD Gida ve İlaç İdaresi (FDA) tarafindan onaylanmış ve opioidbağımlılığı için ofis ortamında uygulanan bir bakım tedavisi imkanısunulmuştur (Fiellin, 2007). Metadon gibi, Buprenorfin ve Buprenorfin/Nalokson ikame tedavisinin hastaneye kabul, morbidite ve mortaliteyi azalttığı da gösterilmiştir (Bell ve ark. 2009). Buprenorfin'nin, opiat antagonistn alokson ile kombinasyonu, tek başına buprenorfin ile aynı yararları sergilemekle beraber potansiyel suistimali azaltma faydas1 da meydana getirmektedir (Mauger, Fraser ve Gill, 2014). Nalokson, öforik bir etki oluşturmadan opioid reseptörüne sıkıca bağlanmaktadır, böylece kısmi veya tam opioid agonistlerinin psikoaktif etkilerini bloke etmekte veya tersine çevirmektedir. Bu nedenle, ilaç öngörüldüğü ş̧ekilde alındığında Buprenorfin'in özelliklerini değiştirmemektedir (Chiang ve Hawks, 2003). Buprenorfin mu opioid reseptörü kısmi agonisti olması nedeniyle reseptörleri kısmen aktive etmektedir. Böyle olunca eroin kullanmakta olan bir kişiye buprenorphine verilmesi halinde mi reseptörlerine kısmi bağlanması nedeniyle yoksunluk başlatılmasına neden olmaktadir (McCance-Katz, 2004).

\section{Buprenorfin ve Metadon Benzerlikleri:}

Buprenorfin ve Metadon, mu reseptörüne bağlanan iki agonisttir. Metadon ve Buprenorfin gibi opioid agonistleri yükselme hissi verse de etkileri diğer yapay opioidlerden daha azdir (Chiang ve Hawks, 2003). Bir bağımlının eroin gibi opiatlara duyduğu isteği azaltmak için konik dozlarda kullanılabilmektedirler. Araştırmalar, her iki ajanın da daha fazla opioid kullanımını engellemek için kendi yerlerine sahip olduğunu göstermiştir (Preston, Bigelow ve Liebson, 1988). Her ikisinin de bir bağımlının eroin gibi zararlı opioidleri kullanmasını engellemek için güvenli ajanlar olduğu kabul edilmiştir. Her iki ilacın da işe yaradığ kanıtlanmış olduğundan, aşırı dozdan ölüm oranını azaltmanın bir yöntemi olduğu düşünülmektedir (Bell, Trinh, Butter ve ark. 2009). Hem Buprenorfin (24-60 saat) hem de Metadon (8-59 saat) uzun etkili ilaçlardır. Metadon ve buprenorphine göre eroin k1sa ömürlü bir opioiddir (Chiang ve Hawks, 2003). Bu şekilde olunca her iki ilacın da bu uzun yarı ömrü, opioid bağımlılığının tedavisinde onları etkili hale getirmektedir.

\section{Buprenorfin ve Metadon Farklılıkları:}

Buprenorfinm $\mu$ reseptörlerinde düşük iç aktiviteye sahiptir. Buprenorfin, Metadon gibi tam bir muagonisti kadar güçlü olmadığı ve daha az analjezi ve öforiye neden olmakla beraber yoksunluk tedavisini hizlı bir şekilde etkilediği bildirilmektedir (Rothman ve ark. 2000). Parsiyel bir agonist olarak, Buprenorfin'in "tavan etkisi" bulunduğu için bir noktadan sonra daha fazla alınması ilacın herhangi bir etkisini arttırmamaktadır. Ek olarak, Buprenorfinm $\mu$ reseptörü için yüksek bir afiniteye sahiptir, bu da ek opioid kullanımının etkilerini azalttığ 1 anlamına gelmektedir. Güçlü bir kappaantagonisti olarak Buprenorfinin, Metadondan daha az öforibulunmaktadır (Kintz, 2002). Yoksunluk belirtileri daha az olmakla beraber doktor kontrolünde olmaz iseenjeksiyon kötüye kullanıma açık olabilmektedir (Rothman ve ark. 2000). Buprenorfin potansiyel olarak solunum depresyonu ve öforiye neden olabilir, ancak etkileri Metadondan çok 
daha azdır (Kintz, 2002). Metadondan daha az suistimal, bağımlılık ve yan etki riski vardır (Hser ve ark. 2014).

Tam agonist olarak Metadon'da tavan etkisi yoktur ve Buprenorfin'e göre daha yoğun yoksunluk belirtileri ortaya çıkarmaktadır. Buna karşın Metadon, Buprenorfin'e göre ağır bağımlılarda daha etkilidir. Aşırı doz alımı nedeniyle Buprenorfin'e göre daha riskli, oral sıvı formu olduğu için de enjeksiyon ile kötüye kullanımı olmaması nedeniyle Buprenorfin'e göre daha avantajlıdır (Gowing, Ali \& White, 2006; Whelan ve Remski, 2012). Ayrıca Buprenorfin'e göre de Metadon'un ilaç maliyetleri daha ucuzdur (Connock ve ark. 2007).

Yapılan çalışmalarda, esnek dozlarda verilen Buprenorfin'in, tedavi gören hastaları tutmada Metadondan istatistiksel olarak anlamlı derecede daha az etkili olduğu tespit edilmiştir (göreceli risk $=0.8$ ), ancak bazı çalışmalarda ise eroin kullanımını bastırmada eşdeğer olduğu tespit edilmiştir. Bununla birlikte, düşük dozlu Metadon'un, düşük veya orta dozdaki Buprenorfin'den daha fazla hastayı tuttuğu da görülmüştür. Orta doz Buprenorfin, alıkonma açısından orta doz Metadon üzerinde hiçbir avantaja sahip değildir ve yasadışı opioid kullanımını baskılamakta daha az etkili olduğu belirlenmiştir (DE S ve ark. 2008; Ray R ve ark. 2000).

Metadon'un esnek doz kullanımından Buprenorfin hastalarda daha üstün olduğu tespit edilmiştir (Mattick ve ark. 2014). 24 haftalık çok merkezli randomize bir çalışmada, metadon Buprenorfine'e karşı \%74'e karşı $\% 46$ oranları ile esnek dozlarda tedaviyi tamamlama başarısı yakalamıştır. Günde 30-32 mg Buprenorfin/Nalokson kullanan bağımlılarda idame tedavide $\% 60$ ve $60 \mathrm{mg} /$ gün veya daha yüksek dozlarda metadon idame tedavisinde ise $80 \%$ başarı elde edilmiştir (Hser ve ark. 2014).

Tablo 1. Metadon Ve Buprenorfin Karşılaştırılması

\begin{tabular}{|c|c|c|c|}
\hline Özellikler & Metadon & Buprenorfin & Avantajlı olan \\
\hline Kullanım Yeri & Klinikte kullanılır & Ofiste ve evde kullanılabilir & Buprenorfin \\
\hline Yoksunluk Belirtileri & Tümüyle ortadan kaldırır & $\begin{array}{l}\text { Çok güçlü bir şekilde } \\
\text { ortadan kaldırır }\end{array}$ & Her ikiside \\
\hline Yükselmişlik Hissi & Yaratır & Yaratmaz & Buprenorfin \\
\hline Ağır Bağımlıların Tedavisinde & Çok başarılı & Bazen başarılı & Metadon \\
\hline Kullanım Şekli & Sıvı Halde içerek & Dil altı & Her ikiside \\
\hline Diğer opioidlere etkisi & $\begin{array}{l}\text { Diğer opioidlerin etkisini } \\
\text { durdurur }\end{array}$ & $\begin{array}{l}\text { Diğer opioidlerle karşılaşırsa } \\
\text { yoksunluk başlatır }\end{array}$ & Metadon \\
\hline Psikolojik Danışmanlık & $\begin{array}{l}\text { Psikolojik Destek } \\
\text { verilmesine imkan sağlar }\end{array}$ & $\begin{array}{l}\text { Psikolojik destek } \\
\text { verilmesine imkan sağlar }\end{array}$ & Her ikiside \\
\hline Ücret & Ucuz & Daha pahalı & Metadon \\
\hline Bilimsel Etkinliği & Son 60 yıldırispatlanmış & Son 20 yıldır ispatlanmış & Her ikiside \\
\hline Yüksek Doz & Riski var & Riski daha az & Buprenorfin \\
\hline Karaciğer yan tesiri & Daha az & Var & Metadon \\
\hline Bağımlılık Şiddeti & Yüksek & Daha az & Buprenorfin \\
\hline Uzun süreli Tedaviyi durdurma & Zor & Nispeten Zor & Buprenorfin \\
\hline Tedavide Başarı & Birbirine benzer oranlar & Birbirine benzer oran & Her ikiside \\
\hline Yan etki & İlk haftada hafif derecede & $\begin{array}{l}\text { Kullanım süresi boyunca } \\
\text { devam eder }\end{array}$ & Metadon \\
\hline
\end{tabular}

\section{Sonuç:}

Farmakoterapi açısından Buprenorfin'in bariz faydalarına ve avantajlarına rağmen (örneğin aşırı doz riskinin büyük oranda azalması), Buprenorfin, opioid bağımlılığının tedavisinde metadonu geçememiştir. Bazı bağımlıların Buprenorfin bazılarının ise Metadon'dan yararlandığını görülmektedir. Her ikisinin etkin olduğu bağımlılar vardır. Bunun da nedeni farklıhasta türlerinin ve hastaların bağımlılık derecelerinin tedavi tercihlerini etkileyebilmesidir. Burada temel amaç; seçenekleri artırarak hastanın değişim motivasyonuna katkıda bulunmaktır. Dolayısıyla farklı hasta türlerine göre gerek Buprenorfin gerekse Metadon kullanımı hastalar için tedavide farklı alternatifler yaratabilmektedir. Hafif ve orta şiddet derecedeki bağımlılarda Buprenorfin şiddetli bağımlılarda ise Metadon seçeneği kullanılabilmektedir Buprenorfin Metadon göre daha emniyetli olarak kullanılabilirken ağır bağımlılık özelliği olan ve yoksunluk krizi şiddetli geçen hastalarda Metadon tercihi öne çıkabilmektedir. Bu tedavi seçeneklerinin artırılması bağımlıların başvurularını da artırmaktadır. Her iki ilaçta hayat kurtarıcı olduğu görülmektedir. Aslında bu ajanların birbirinden farklı üstünlükleri ve zayıflıkları birbiri yerine geçen ajanlar olarak görülmemelidir. Tam tersine her iki ajan da farklı hasta gruplarında, uzmanın tercihine ve hastanın durumuna göre, tedavi zenginliği anlamında değerlendirilmelidir. Bu da daha çok bağımlı için daha geniş bir tedavi yelpazesi oluşturmaktadır. KKTC ve Türkiye gibi bazı ülkelerde halen Buprenorfin'in tek ilaç seçeneği olarak kullanılması ve Metadon'un kullanılmaması ciddi bir eksikliktir. Dolayısıyla her iki ajanı da tüm dünya hekimlerinin kullanımına sunulması bugünün bilimsel gerçeğidir. 


\section{Kaynaklar}

AAPM, APS ve diğ. (1997). Kronik ağrının tedavisi için opioid kullanımı. Amerikan Ağrı Tıbbı Akademisi ve Amerikan Ağr1 Derneği'nden bir uzlaşma açıklaması. Klinik Ağrı Dergisi. 13:68 .

Amato, L., Minozzi, S., Davoli, M., Vecchi, S., (2011).Psychosocial and pharmacological treatments versus pharmacological treatments for opioid detoxification. Cochrane Database Syst Rev. 9:CD005031.

Auriacombe, M.,Fatseas, M., Dubernet, J., Daulouede, JP., Tignol J.(2004). French field experience with buprenorphine. Am J Addict. 13:S17-S28.

Bavelloni, A., Piazzi, M., Raffini, M., Faenza I., ve Blalock, W. L. (2015). Prohibitin 2: At a communications cross roads. IUBMB Life, 67(4), 239-254.

Bell, J., Trinh, L., Butler B., Randall, D., Rubin G.,(2009). Comparing retention in treatment and mortality in people after initial entry to methadone and buprenorphine treatment. Addiction. 104:1193-1200.

Caplehorn, JR.,Drummer O.H. (1999).Mortality associated with New South Wales methadone programs in 1994: lives lost and saved. Med J Aust. 170:104-9.

Chiang, C.N., Hawks, RL. (2003).Pharmacokinetics of the combination tablet of buprenorphine and naloxone. Drug Alcohol Depend. 70(Suppl 2):S39-S47.

Connock, M., Juarez-Garcia, A., Jowet,t S., Frew, E., Liu, Z., Taylor, R., et al. (2007).Methadone and buprenorphine for the management of opioid dependence: a systematic review and economic evaluation. Health Technol Assess.11:1-171

CSAT (Madde Bağımlılı̆̆ Tedavi Merkezi) Rockville, MD: Madde Bağımlılı̆ı ve Ruh Sağlığı Hizmetleri Yönetimi; 2004. Opioid Bağımlılı̆̆ının Tedavisinde Buprenorfin Kullanımı için Klinik Kılavuz. Tedavi

İyileştirme (Protokol (TIP) 40 Serisi. DHHS Yayın No. (SMA) 04-3939. De, S., Jain, R., Ray, R., Dhawan, A., Varghese, S. T. (2008).Assessment of differential doses of buprenorphine for longterm pharmacotherapy among opiate dependent subjects. Indian J Physiol Pharmacol. 52:53-63.

Fiellin, D.A. (2007). The first three years of buprenorphine in the United States: experience to date and future directions. $J$ Addict Med. 1:62-67.

Gowing, L., Ali, R., White, J.(2006). Buprenorphine for the management of opioid with drawal. Cochrane Database Syst Rev.:CD002025.

GwinMitchell, S., Kelly, SM., Brown BS., et al. (2009). Uses of diverted methadone and buprenorphine by opioid-addicted individuals in Baltimore, Maryland. Am J Addict. 18:346-355.

Hadland,SE., Bagley, S.M., Rodean, J., Silverstein, M., Levy, S., Larochelle, M.R., Samet, J.H., Zima, B.T. (2018). Opioid Kullanım Bozukluğu Olan Gençlerin Bakımında Zamanında Bağımlılık Tedavisi ve Erken İlaç Tedavisi Derneği.1; 172 (11): 1029-1037.

Hickman, M., Yön, C., Killing, K A.G., Marsden, J., Millar, T., Strang, J., Telfer, M., Vickerman, P., Macleod J. (2018).Buprenorfin ve metadonun mortalite üzerindeki etkisi: Birleşik Krallık\&\#39;taki birinci basamak kohort çalışması.113 (8): 1461-1476.

Hser, YI., Saxon, AJ.,Huang D., Hasson, A., Thomas, C., Hillhouse, M., Jacobs, P., Teruya, C., McLaughlin, P., Wiest, K., Cohen, A., Ling, W. (2014). Treatment retention among patients randomized to buprenorphine /naloxone compared to methadone in a multi-site trial. Addiction,109(1): 79-87.
Huxtable, C.A., Roberts, L.J., Somogyi, A.A., MacIntyre, P.E.(2011). Opioide toleranslı hastalarda akut ağrı yönetimini : Büyüyen bir zorluk.Anestezi Yoğun Bakım. 39 (5): 804-23.

Johnson, R.E., Chutuape, M.A., Gerilim, E.C., Walsh, SL., Stitzer, ML., Bigelow, G.E.(2000). Opioid bağımlılığı için LAAM, Buprenorfin ve Metadonun karşılaştırılması. New England Tip Dergisi. 343:1290-1297.

Johnson, R.E., Strain, E.C., Amass L. (2003). Buprenorphine: how to use it right. Drug Alcohol Depend. 70:S59-S77. Johnson, R.E., Jaff, .H., Fudala, P.J. (1992). Opioid bağımlılı̆̆g için kontrollü bir buprenorfin tedavisi denemesi. Amerikan Tabipler Birliği Dergisi. 267:2750-2755.

Kintz, P. (2002). A new series of 13 buprenorphine-related deaths. Clinical Biochemistry, 35: 513- 516.

Mattick, R.P.,Breen, C., Kimber,J., Davoli, M. (2014).Buprenorphine maintenance versus placebo or methadone maintenance for opioid dependence. Cochrane Database Syst Rev 2: CD002207.

Mauger, S.,Fraser, R., ve Gill, K., (2014). Utilizing buprenorphine-naloxone to treat illicit and prescription-opioid dependence. Neuro psychiatric disease and treatment, 10, 587598.

McCance-Katz EF., (2004). Office based treatment of opioid dependence with buprenorphine. Harvard Review of Psychiatry, 12: 321-338

Papadakis, M. A., McPhee, S. J. (2014). Current Medica 1Diagnosis and Treatment, Mc Graw Hill: New York.

Öğütçü Z.,Çelikay H., Ender A. (2019). Madde Kullanım Geçmișli Bireylerin Olumsuz Otomatik Düșünceleri ve Öğrenilmiş Çaresizlik Örüntülerinin İncelenmesi. Kıbrıs Türk Psikiyatri ve Psikoloji Dergisi, 1(1), 22-30.

Preston, K.L., Bigelow, G., Liebson, I. (1988).Buprenorphine and naloxone alone and in combination in opioid-dependent humans. Psychopharmacology. 94:484-490.

Ray, R., Pal, H., Kumar, R., Maulick, P., Mangla, R. (2004). Post-marketing surveillance of buprenorphine. Pharmaco epidemiol Drug Saf. 13:6,15-9.

Rassool, G., (2010). Addictionfornurses. Chichester, West Sussex, UK. Wiley-Blackwell.

Rettig, R.A.,Yarmolinsky, A. (1995).Institute of Medicine (US) Committee on Federal Regulation of Methadone Treatment; Federal Regulation of Methadone Treatment. Washington (DC): NationalAcademiesPress (US); ExecutiveSummary. Availablefrom: https://www.ncbi.nlm.nih.gov

Rosenblum, A., Marsch, L.A., Joseph, H., Portenoy, R.K. (2008), Opioids and the Treatment of Chronic Pain: Controversies, Current Status, and Future Directions. Exp Clin Psychopharmacol.16(5): 405-416.

NDIC Metadon saptırma, kötüye kullanma ve kötüye kullanma: endişe verici oranda artan ölümler. Yayın tarihi: 16 Kasım 2007; belge numarası: 2007-Q0317-001. Erişim tarihi: 23 Temmuz 2019.

Roche, A., McCabe, S., Smythe, BP. (2008). Yasadıșı metadon kullanımı ve gençlerde afyon bağımlılığ 1 için tedaviye erişim. Avrupa Bağımlılı̆̆ Araştırma. 14:219-225.

Rothman, R.B.,Gorelick, D.A., Heishman, S.J., Eichmiller, P.R., Hill, B.H., Norbeck J., et al. (2000). Opioid bağımlılığının tedavisinde fonksiyonel bir opioid kappaantagonistinin açık etiketli bir çalışması. J Alt Suistimal Tedavi.18:277-81.

Sohler, N.L., Li, X., Kunins, H.V., et al. (2010). Home- versus office-based buprenorphine induction for opioid-dependent patients. J Subst Abuse Treat. 38:153-159. 
United Nations Office on Drugsand Crime. (2009). World Drug Report. 152-6.

Whela, P.J ve Remski, K. (2012). Buprenorphine vs methadone treatment: A review of evidence in both developed and developing worlds. Journal of neurosciences in rural practice, $3(1), 45-50$.

Wolff, K. (2005). Madde Bağımlılığı: Değiştirme ilaçları (metadon ve buprenorfin) Oxford: Elsevier.
World Health Organization, Department of mental health and substance misuse. Proposal for the inclusion of buprenorphine in the WHO model list of essential medicines. WHO. 2004. [Lastaccessed:2011].

Wright, N.M.C., Sheard, L., Adams, C.E., Rushforth, B.J., Harrison, W., Bound, N., Hart, R., Tompkins ,C.N.E. (2011).Comparison of methadone and buprenorphine for opiate detoxification (LEEDS trial): arandomised controlled trial. British Journal of General Practice.61 (593): e772-e780.

Yule, A. M., Lyons, R. M., ve Wilens, T. E. (2018).Opioid Use Disorders in Adolescents-Updates in Assessment and Management. Current pediatrics reports, 6(2), 99-106. 